\title{
Corrections to: Atomic Origins of Friction Reduction in Metal Alloys
}

\author{
Shengfeng Cheng ${ }^{1}\left[\right.$. Michael Chandross ${ }^{2}$
}

Published online: 22 June 2021

๑) Springer Science+Business Media, LLC, part of Springer Nature 2021

\section{Correction to: Tribology Letters (2021) 69:69}

https://doi.org/10.1007/s11249-021-01442-w

The original version of this article unfortunately contained a mistake. The presentation of Figs. 6 and 7 was incorrect in the original publication. The correct versions of Figs. 6 and 7 are given below.

The original article can be found online at https://doi.org/10.1007/ s11249-021-01442-w.

Shengfeng Cheng

chengsf@vt.edu

Michael Chandross

mechand@sandia.gov

1 Department of Physics, Center for Soft Matter and Biological Physics, Macromolecules Innovation Institute, and Department of Mechanical Engineering, Virginia Polytechnic Institute and State University, Blacksburg, VA 24061, USA

2 Material, Physical and Chemical Sciences Center, Sandia National Laboratories, Albuquerque, NM 87185, USA 


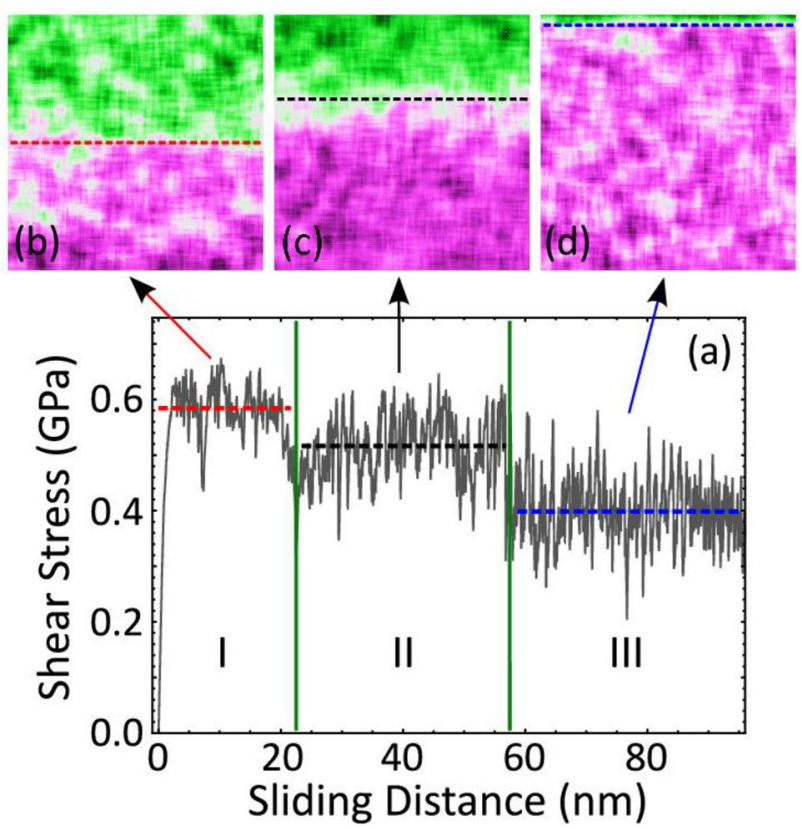

Fig. 6 Contact between two Ag slabs under shear: a friction trace as a function of sliding distance showing three distinct regimes: I and b high friction when sliding occurs primarily along slip planes near the initial interface between the two slabs; II and $\mathbf{c}$ intermediate friction as the sliding plane moves toward the upper loading layer; III and d low friction when sliding occurs primarily at the boundary of the loading layer. In $\mathbf{b}-\mathbf{d}$, the local shear velocity is shown with greenpink density plots with green indicating $1 \mathrm{~m} / \mathrm{s}$ and pink indicating -1 $\mathrm{m} / \mathrm{s}$, and the dashed line in each plot indicates the location of the slipplane (Color figure online)

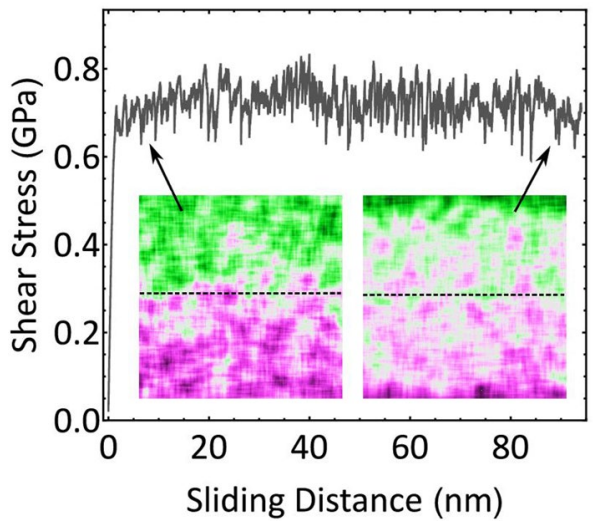

Fig. 7 Friction trace as a function of sliding distance for a contact between two $\mathrm{Ag}-\mathrm{Cu}$ slabs under shear. Inset: green-pink density plots (with the same color scale as in Fig. 6) of local shear velocity showing the location of the slipping plane (dashed lines) in the early and final stage of the sliding process (Color figure online)

Publisher's Note Springer Nature remains neutral with regard to jurisdictional claims in published maps and institutional affiliations. 